\title{
360-degree video in education: An overview and a comparative social media data analysis of the last decade
}

\author{
Georgios Lampropoulos ${ }^{1,2^{*}}$ (D), Vassilis Barkoukis ${ }^{3}$, Kevin Burden ${ }^{4}$ (i) and Theofylaktos Anastasiadis ${ }^{3}$ (i)
}

\author{
*Correspondence: \\ lamprop.geo@gmail.com \\ ${ }^{1}$ Department of Information \\ and Electronic Engineering, \\ International Hellenic \\ University, Thessaloniki, \\ Greece \\ Full list of author information \\ is available at the end of the \\ article
}

\begin{abstract}
Due to its immersive and interactive nature, 360-degree video is becoming ever more popular. However, little is known about the public's viewpoints and attitudes regarding the use of this emerging technology in educational contexts. This study reviews the research evidence for $360^{\circ}$ video, virtual learning environments and social media and presents related studies. Moreover, the methodology, the tools and the analysis process used to comparatively analyze social media data are presented and the results that arose are showcased. The use of $360^{\circ}$ video in education is discussed and directions for future research are given. Based on the data from the last 10 years, the main findings of the study show that $360^{\circ}$ video and its use in educational settings are recognized positively by the public who mostly express anticipation, trust and joy when referring to it. Nonetheless, teachers are unfamiliar with $360^{\circ}$ video and do not have the necessary technical skills to develop educational material using it or incorporating it into teaching activities. Finally, $360^{\circ}$ video is proven to be an effective educational tool which satisfies the emerging educational needs, enriches the teaching and learning process and promotes students' motivation, active participation and engagement, rendering, thus, learning more effective.
\end{abstract}

Keywords: 360-degree video, 360 video, Educational technology, Immersive learning, Immersive technologies, Social media, Technology-enhanced learning, Data analysis, Sentiment analysis, Virtual reality

\section{Introduction}

As it was aptly described over a decade ago, today's students are no longer the people our educational system was designed to teach (Prensky, 2001). Therefore, education methods should be adapted in such a way as to accommodate these evolving and varying learning styles and emerging educational needs and requirements (DiLullo et al., 2011). In order to improve the quality of education to meet these new requirements and adjust to the new conditions, Information and Communication Technologies (ICT) have been integrated into education and technology-enhanced learning methods have been implemented (Alexander et al., 2019; Henard and Roseveare, 2012). Moreover, technology-enhanced learning has become a fundamental part of 21st

(c) The Author(s), 2021. Open Access This article is licensed under a Creative Commons Attribution 4.0 International License, which permits use, sharing, adaptation, distribution and reproduction in any medium or format, as long as you give appropriate credit to the original author(s) and the source, provide a link to the Creative Commons licence, and indicate if changes were made. The images or other third party material in this article are included in the article's Creative Commons licence, unless indicated otherwise in a credit line to the material. If material is not included in the article's Creative Commons licence and your intended use is not permitted by statutory regulation or exceeds the permitted use, you will need to obtain permission directly from the copyright holder. To view a copy of this licence, visit http:// creativecommons.org/licenses/by/4.0/. 
century education as it allows easy and rapid access to information and services and renders the creation of immersive virtual learning environments feasible. Based on a study conducted by European University Association, 91\% of European Higher Education institutes have already delivered blended and distance learning courses (Gaebel et al., 2014).

Furthermore, the recent advances in ICT and Extended Reality (XR) technologies as well as the emphasis on pedagogy in student-centered learning have paved the way for using immersive technologies in educational activities. XR technologies involve immersive technologies such as augmented reality and virtual reality. Virtual reality refers to environments or realities created by computers designed to simulate a person's physical presence in specific real or artificial environments which perceptually surround users and are presented in such a way that they can be regarded to be true. It is differentiated from augmented reality which refers to technological applications of computer units that enrich and enhance users' physical environment with additional information and virtual objects in real time (Lampropoulos et al., 2020). In order to create highly interactive and immersive educational environments and experiences, the use of $360^{\circ}$ video, augmented reality and virtual reality are becoming more and more popular as they enable users to directly experience and interact with virtual contents and environments. This immersive nature blends well with existing educational pedagogies such as those rooted in constructivist ideals since they facilitate communication, interaction, collaboration and enhance engagement (Huang et al., 2010). Dede (2009, p. 66) defined immersiveness as "the subjective impression that one is participating in a comprehensive, realistic experience" and in a subsequent study he highlighted the potentials of immersive environments as a means to improve learning outcomes by promoting situated experiences, various perspectives as well as communication and knowledge acquisition and transfer (Dede, 2009). Additionally, the engagement, motivation and active participation of students are regarded as key contributors to the learning and teaching process as well as towards learning and academic success (Appleton et al., 2006; Fredricks et al., 2004; Hew, 2016; Roorda et al., 2011; Wang and Fredricks, 2014) and they can all be reinforced through the use of immersive technologies which offer richer virtual environments and more vivid experiences irrespective of users' location (McKenzie et al., 2019; Rupp et al., 2016). The sense of presence within a virtual environment is a topic which has attracted a lot of interest. Although the terms presence and immersion seem to be alike, there is a significant difference between them as presence refers to subjective psychological response of a user experiencing a virtual environment while immersion to the objective level of sensory fidelity (Slater, 2003). Particularly, presence can be defined as a sense of being within a virtual world or as a perceptual illusion of being in a place that you are aware of not being there (Slater et al., 1994; Slater, 2018).

The remainder of this paper presents the main aims, motivations and incentives of this study, goes over recent related work and showcases the concept of 360-degree video and its application in educational settings. Furthermore, it analyzes the methodology followed and the results drawn based on a comparative social media data analysis of the last decade. Finally, it summarizes and discusses the main findings and drawn conclusions, goes over the challenges and limitations and provides directions for future research. 


\section{Aims, motivations and incentives}

Our motivations and incentives derive from the concept of crowd wisdom in which the aggregation of information of public groups yields more efficient results while leveraging the collective knowledge and decisions of a group of individuals instead of relying on a handful of experts' opinions (Surowiecki, 2004). That is the reason why we opted to base our work on the public's viewpoints and attitudes. This type of data retrieval and analysis can be regarded as a form of crowdsourcing. Crowdsourcing is the act of outsourcing a task or a job conventionally carried out by a definite agent to an undefined public (Howe, 2006) and is based on the fact that a higher value is created when people work collectively in virtual and physical networks and not independently. Nowadays, both concepts of crowd wisdom and crowdsourcing are ubiquitous due to the technological advancements and the development of user-centered applications. Moreover, the rise of social media and their continuously increasing number of users have led to the creation of an immense volume of data, known as Big Data, which is exponentially increasing daily (Wu et al., 2013). Social media enable users to publicly share their opinions and viewpoints in real time. Additionally, these platforms provide useful tools such as Application Programming Interfaces (API) to make the available open data easily accessible. It goes without saying that social media along with the tools they offer can be used to extract invaluable knowledge regarding the public's opinion on certain matters.

For the purposes of this study, the Twitter's API was used to access and collect open raw data of text (tweets) that users chose to share publicly. Analyzing the text contents of the tweets in order to generate new knowledge and results was its main focus. This specific platform was selected since it is regarded as the go to platform for people to share their opinion on matters as soon as they occur or on breaking news and it urges them to be concise and precise in their posts due to the limited amount of characters per tweet (Bruns et al., 2012; Java et al., 2007; Phuvipadawat and Murata, 2010).

Furthermore, this study expanded over the related Twitter data of the last decade so as to have a better understanding and provide a more complete overview of the changes, evolution and advancements of this innovative technology both in general as well as in the educational sector in particular. Specifically, this study involved the identification and the collection of Twitter data from January 2010 to December 2020 regarding (1) the general use of $360^{\circ}$ video and (2) the use of $360^{\circ}$ video in education as well as the processing, analysis and visualization of the retrieved data in order to better comprehend the related public's viewpoints and attitudes and answer our two main research questions which are:

- RQ1: What public attitudes and perspectives about and towards the use of $360^{\circ}$ video in general are evident in social media (Twitter) posts?

- RQ2: What public attitudes and perspectives about and towards the use of $360^{\circ}$ video in education are evident in social media (Twitter) posts?

\section{0-degree video}

The exponentially increase in online content, the more affordable and cost-effective technologies as well as the drastic improvements afforded to mobile technologies, have brought about an interest in the use of $360^{\circ}$ video and immersive technologies in 
education. In contrast to conventional videos which offer a very restrictive perspective, $360^{\circ}$ video provides a spherical view with multiple viewing angles and perspectives. Moreover, the contents of $360^{\circ}$ video are in an omnidirectional form and can either be computer generated or captured from the real world and as a result, users are able to view everything within the camera range, thus more interactive, immersive, engaging and realistic experiences can be created. Furthermore, $360^{\circ}$ video aligns well with existing pedagogical approaches and due to their immersive qualities, students perceive being physically present in a virtual environment and thus, they become more absorbed and engaged in learning activities (Rupp et al., 2016). Additionally, $360^{\circ}$ video can affect students' emotional response to the learning climate in a positive way (Ulrich et al., 2021).

Existing evidence suggests that $360^{\circ}$ video has the potential to offer interactive learning experiences so it is highly likely that the positive learning aspects will be increased while the negative ones will be reduced through an interactive design and development process (Preece et al., 2015). Furthermore, along with the advancement of lower cost technologies, the increased online video content and the progressive integration of $360^{\circ}$ video in social media platforms has led to the creation of an exponentially growing collection of online $360^{\circ}$ videos (Snelson and Hsu, 2020). Additionally, as $360^{\circ}$ video provides users with spherical views and renders their interaction and communication with the virtual world around them feasible, it enhances the feeling of immersion (Ranieri et al., 2020) and through the illusion that the experience perceptually surrounds them, they feel a sense of presence within it (Hodgson et al., 2019). $360^{\circ}$ video affects the emotional response to the learning climate positively, it is cost-effective and it can increase the effectiveness of e-learning (Ulrich et al., 2021). Due to the visual and auditory immersion which is provided by $360^{\circ}$ video, distraction that may impede the effectiveness of learning and teaching may be overcome and practical skills training can be enhanced.

Ranieri et al. (2020) noted that research into the use of $360^{\circ}$ video in educational setting is at its very early stages. Therefore, given the limited empirical evidence for $360^{\circ}$ video as an effective educational tool, the present study aims at comprehending the general public's viewpoints and attitudes regarding the use of $360^{\circ}$ video as a whole as well as their utilization in educational settings through the lens of social media. In that view, the main aims of this study are to analyze the public's opinion regarding the use of $360^{\circ}$ video as well as their specific use in education through the analysis of the publicly available and user-generated content on social media. Consequently, $360^{\circ}$ video, either on their own or in combination with other immersive technologies, help students explore new interactive environments and perspectives as well as experience emotions and situations which would be impossible otherwise. When used in conjunction with XR technologies, contemporary virtual learning environments, which enable students to experience and interact with virtual content, can be created. These environments provide students with engaging, realistic and authentic scenarios and experiences in which they can explore, interact and communicate with virtual contents while simultaneously offering them a sense of embodiment and a feeling of belonging (Kilteni et al., 2012). Therefore, $360^{\circ}$ video can be regarded as an innovative pedagogical practice which, when applied in educational settings, can yield a number of merits and increase students' overall engagement. 


\section{Related work}

Rupp et al. (2016) carried out a study in order to assess the immersiveness of educational $360^{\circ}$ video as well as their future VR expectations on subjective experiences. Their experiment involved sixty-three (63) participants (aged 18-30) who viewed a 360-degree educational video from various devices having as a main goal to gain as much knowledge as possible. They highlighted that immersive experiences might enhance the learning experience by increasing interest in the learning content. Their findings showcased that the feelings of presence were greater when the experiences were more immersive. However, they quoted that the novelty of such experiences might overwhelm learners and lead to less information retention. Roche and Gal-Petitfaux (2017), investigated the use of $360^{\circ}$ video in physical education teacher education so as to describe preservice teacher activity in a workshop. Particularly, they tried to pinpoint what kind of activity the students would deploy while viewing $360^{\circ}$ video and based on the chosen activity which design would be the most useful for a video-enhanced teacher learning environment for learning to teach physical education. Their study followed the course-of-action theory (Theureau, 2003) and was based on the hypothesis of situated action Suchman 1987 and situated cognition Hutchins 1995 . Based on their results, $360^{\circ}$ video constitutes a novel way to utilize video in teacher training as it allows preservice teacher to live an immersive experience. Finally, they quoted that designing $360^{\circ}$ video enhanced environments can lead to the development of immersive situations that work well for learning to teach physical education but in order to comprehend the situation in depth, $360^{\circ}$ video should utilize wide angles or points of view.

Aiming at reaping the benefits of $360^{\circ}$ video in language learning, Berns et al. (2018) developed an application which offers students an immersive and fully interactive learning environment. More specifically, in order to foster learners' language competencies, they looked into the potentials of chatbots and $360^{\circ}$ video applications in creating immersive experiences. A Technology Acceptance Model based questionnaire (Liu et al., 2017) was used to assess their application effectiveness and gather information regarding students' learning experience and attitudes. Based on their results, students, in their assessment, neither denied nor questioned the potentials of their application and had a positive attitude towards it due to its attractiveness and impressiveness and not due to the effect of novelty. With a view to evaluating the effect that 360 operative videos have on information retention and attentiveness in surgical education, Harrington et al. (2018) conducted a cross-over study in which they appraised $360^{\circ}$ video in comparison to two dimensional (2D) ones based on students' perspectives. In total forty (40) preclinical undergraduate students (mean age 23.2) took part in their experiments. Their results showcased that compared to $2 \mathrm{D}$ video $360^{\circ}$ video offered significantly higher engagement and attentiveness benefits but there were no significant variances in information retention. It is worth noting that the participants of this experiments expressed that when it came to $360^{\circ}$ video, the overall experience was more immersive and characterized it as both entertaining and beneficial to learning. Moreover, Hodgson et al. (2019), examined the use of $360^{\circ}$ video in immersive VR applications in higher education. Their experiment involved students from two undergraduate courses that had adopted VR as a classroom learning method. According to the results of their questionnaire, students assessed $360^{\circ}$ video and VR in a positive manner and expressed greater learning 
satisfaction while also experiencing more opportunities for professional skill rehearsal. Finally, they pinpointed that interaction through these means interest and curiosity can be promoted and professional competence reinforced. Aiming at comprehending the impact that the incorporation of $360^{\circ}$ video into class content and educational settings have on students and teachers, McKenzie et al. (2019) presented an exploratory case study regarding the use of $360^{\circ}$ video in educational settings. More specifically, they conducted experiments in the classroom using $360^{\circ}$ video to determine if they have an impact on students' feelings of presence with class content as well as how the inclusion of $360^{\circ}$ video affects the teaching experience. In their study, they used both quantitative and qualitative aspects. Their results showcased that $360^{\circ}$ video can constitute an alternative immersive content presentation means for students as well as help them improve their sense of presence. Additionally, they stated that these interactive and immersive experiences might distract students' attention from the teaching staff and the image quality and file size that the given learning environment requires should be taken into account. Finally, they stated that the small number of participants that viewed the $360^{\circ}$ video was a limitation to their study.

Violante et al. (2019) investigated the use of $360^{\circ}$ video and interactive virtual technologies in engineering education. Their main aim was to assist in identifying a methodology for designing and using $360^{\circ}$ video as interactive learning contents that encourage greater student engagement. Moreover, they utilized a quantitative survey, in which thirty (30) students (aged 20-24) participated, to rate students' perceived levels of engagement in regard to behavioral, cognitive and emotional engagement. According to their results, the students evaluated the use of $360^{\circ}$ video as highly immersive and engaging and as a means that increased their involvement, initiation and action. In addition, students also reported feeling more creative and less worried and being less distracted as they focused and concentrated more on the contents of the $360^{\circ}$ video. Finally, when using $360^{\circ}$ video, students expressed higher levels of interest, enjoyment and concentration which according to Shernoff et al. (2014) foster optimal learning. In their research, Ulrich et al. (2021) presented reports regarding the use of $360^{\circ}$ video in healthcare education which involved a controlled experiment in which eighty-one (81) physiotherapy students participated. Their approach used a $3 \times 3$ factorial design with three treatment groups and measured their academic performance, the perceived user satisfaction and their perception of learning climate. In order to assess academic performance, the students were tested before and after each treatment while for the assessment of user satisfaction and perception of learning climate the instrument presented in Chou and Liu (2005) was adapted. According to their findings, there were no differences regarding the academic results among $360^{\circ}$ video, regular video and traditional teaching. However, in regard to learning satisfaction as well as internal and external perspectives of the students' learning satisfaction, traditional teaching was equal or better than both $360^{\circ}$ video and regular video. Finally, they highlighted that even though $360^{\circ}$ video offered more presence compared to regular video, neither of them contained any interactivity which resulted in them being either just as effective or outperformed by traditional teaching.

When it comes to $360^{\circ}$ video, the way audiences process information may be affected since it contains new audiovisual grammar (Dooley, 2017). With the aim of coping with this issue, (Barreda-Ángeles et al., 2020) went over the significance of the immersion in 
the audiences' cognitive access to information which according to Dunaway and Soroka (2021) is closely related to learning as it facilitates information acquisition and process. In order to analyze how immersion affects information processing as well as the mediating effects of arousal and presence, they conducted an experiment which included psychophysiological and self-report methods and which involved thirty-seven (37) volunteers (aged 19-43). Their results showcased that immersive presentation of narrated events through $360^{\circ}$ video brought about feelings of presence and emotional arousal. Finally, they highlighted that in order to create immersive narratives that not only inform audiences but also engage them, a careful design of the overall experience would be of great significance. Furthermore, Snelson and Hsu (2020) conducted a scoping review through a systematic process to identify trends in peer-reviewed research journal articles about the emerging research of educational360-degree video in VR. With the aim of displaying the extent and nature of research regarding $360^{\circ}$ video as well as the generated educational benefits and drawbacks, they identified and analyzed twelve (12) articles that met their research criteria and which included nine (9) different content areas that promoted immersive learning. Based on their results, the most important aspect of $360^{\circ}$ video in education was immersiveness as every one of the involved studies included some type of immersive VR experience. In addition, the results of a word frequency query revealed that the word immersive or some variant was one of the most used words within these articles. Thus, they indicated that the concept of immersiveness and the role of VR are closely related to the use of $360^{\circ}$ video in educational settings. In addition, the results in relation to the effect of $360^{\circ} \mathrm{VR}$ video on learning were mixed but nonetheless, the learners showcased enjoyment throughout the whole experience. Finally, they highlighted that the use of $360 \mathrm{VR}$ video could be more beneficial and appropriate for certain types of learning. Ranieri et al. (2020) conducted a systematic literature review with the aim of identifying how $360^{\circ}$ video is currently being used in different educational settings as well as the various issues and opportunities that occur. Based on their results, even though 360-degree video is still at its infancy and there is a need for more studies to be conducted, it can be used as a supplementary educational means which can increase students' satisfaction and involvement.

As the above-mentioned studies show, even though traditional teaching cannot be fully replaced by technology, $360^{\circ}$ video is a contemporary technology that can be used to enhance the overall teaching and learning process. Due to its immersive nature and the interactive experiences that $360^{\circ}$ video offers, it can facilitate and enrich traditional teaching and can be used in blended learning approaches and methodologies (e.g. flipped classroom) to further improve students' immersiveness, engagement and overall learning experience. Finally, when used in a student-centered way, $360^{\circ}$ video can constitute a vital educational tool that can meet the new educational needs and requirements.

\section{The present study}

Even though prior research looked into the usefulness of $360^{\circ}$ video in various educational domains, there is a limited number of studies that compare $360^{\circ}$ video with traditional teaching methods. Furthermore, despite the fact that most studies support the positive effects that the use of $360^{\circ}$ video brings in various sectors, still little is known about the viewpoints and attitudes of the general public regarding its use in education. 
With a view to bridging this gap, the present study employed a social media data analysis on public's viewpoints and attitudes concerning $360^{\circ}$ video as well as its use in educational settings. Before going on to present and analyze the used methodology and the drawn results from the two (2) data sets of this study and in order for it to be better comprehended, it is vital to briefly go over the concept of social media.

\section{Social media}

As this study focuses on retrieving data from social media, it is essential to define social media and their selection as our data source. Social media nowadays constitute an integral part of modern society. Social media enable users to create a network of personal connections and are used to communicate, collaborate and interact within a common information space as they offer features that increase awareness and support informal communication and allow users to be involved in various social and interactive activities (Boyd and Ellison, 2007; Pallis et al., 2011). Having transparency, bottom-up communication, collaboration, personalization and knowledge as well as information and knowledge sharing as their foundations (Makkonen et al., 2019), social media platforms are based on the ideological and technological foundations of Web 2.0 and promote horizontal knowledge sharing (Kaplan and Haenlein, 2009; Zolkepli and Kamarulzaman, 2015). Additionally, social media are ruled by hybrid media logic (Gil de Zúñiga et al., 2017) and they can be considered as virtual communities (Dwyer et al., 2007) that foster the fundamental motivation factors of a sense of belonging and socialization (Özgüven and Mucan, 2013).

As social media enable users to create and publish content in various formats and make it instantly available to the public, they have drastically changed how people share and co-create information and knowledge, communicate and collaborate. Therefore, social media have become a significant means for web content discovery, information dissemination, debate as well as opinion and knowledge sharing. Finally, due to the sheer amount of user generated and opinionated publicly available content within social media networks, social media can be utilized to conduct data analyses in order to comprehend the wisdom of the crowd regarding specific matters. For all these reasons, we opted to use social media and Twitter in particular as a fundamental tool of this study in order to comprehend the public's viewpoints regarding the use of $360^{\circ}$ video as a whole and their utilization in educational settings.

\section{Methodology}

In order to meet the requirements, answer the main research questions and fulfill the aims of this study successfully, the methodology described below, which is also displayed on Fig. 1, was followed:

- Data requirements: As data quality affects the analysis drastically and consequently the conclusions drawn, the high quality of data is significant. In order to ensure data validity, accuracy, completeness, consistency and uniformity, specific aims were set regarding the data retrieval, collection, analysis and visualization processes such as the selection of time periods, variables, sources etc. 
Fig. 1 Methodology

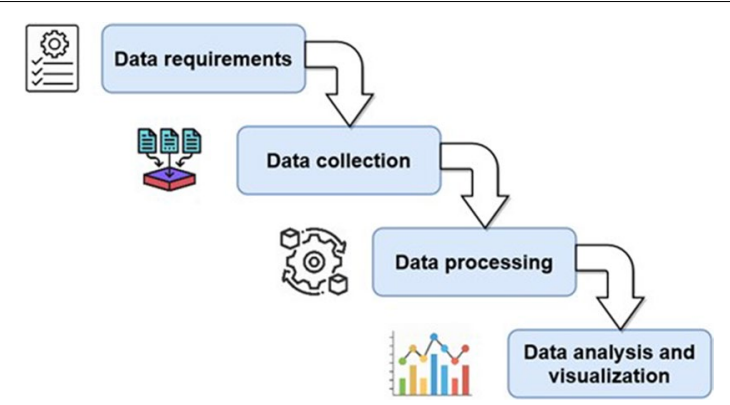

- Data collection: In order to get the public's viewpoints and attitudes regarding $360^{\circ}$ video as well as its use in educational settings, the Twitter social networking service was used. After testing various keywords both separately and in combination, we resulted in using the keywords 360video, 360 degree video, 360-degree video, $360^{\circ}$ video to acquire public's opinion on $360^{\circ}$ video and the same keywords were used in combination with the keywords education, university, higher education, professional development, school to obtain their viewpoint on the specific use of $360^{\circ}$ video in education. For the study use case, data from Twitter over the period of January 2010 to December 2020 was collected. In total, 691,714 tweets regarding the $360^{\circ}$ video were collected out of which 4721 tweets corresponded to the public's opinion on the use of $360^{\circ}$ video in educational settings. It is worth noting that only tweets that contained either one of the keywords for the first data set or a combination of them for the second one got retrieved. In this way, we could be certain that the tweets referred to the technology of $360^{\circ}$ video. Moreover, all the publicly available information was stored for each tweet. That is, id, permalink, date, author_id, username, location, text, hashtags, mentions, urls, retweets and replies. It is evident that users' private information or information that they chose not to share publicly cannot be retrieved.

- Data processing, cleaning and storage: In order to create clean data sets, the collected data was processed. More specifically, the text was converted into lowercase and the punctuations, single characters, URLs and stop-words were omitted where necessary and the abbreviated words were expanded. Both data sets which included the retrieved tweets were stored in Comma-separated Values (CSV) files as well as in JavaScript Object Notation (JSON) format files to enhance the overall usability, flexibility and extensibility.

- Data analysis and visualization: After creating the two data sets, data analysis was conducted (a) on an annual basis and (b) throughout the period of January 2010December 2020 as a whole. For the data visualization process, the results of the data analysis were showcased through graphs which were specifically generated for each of the following cases: total number of tweets, most frequently used words, most frequently used hashtags, most frequently used mentions, most active users, tweets per given interval and tweets per country. 


\section{Sentiment analysis}

Sentiment analysis is widely applied in order to analyze and better identify and comprehend crowd sentiment regarding specific matters. Particularly, it is contextual text mining which identifies and extracts subjective information and affective states in source material through the use of Natural Language Processing (NLP), computational linguistics, biometrics and text analysis. Sentiment analysis can be regarded as the interpretation and classification of emotions within text data. Two different sentiment analysis methods, namely polarity and emotional detection, were used for the purposes of this case study. More specifically, in order to identify the crowd's basic viewpoints (e.g. positive, negative or neutral) regarding the main research questions, basic polarity detection, that is binary text classification, was conducted. The open-source library TextBlob was used as a basis for the lexicon-based sentiment analysis (Loria et al., 2014) and its results were further validated through the use of Valence aware dictionary for sentiment reasoning (VADER) which is a rule-based tool for social media text sentiment analysis (Hutto and Gilbert, 2014). Moreover, with a view to detecting the sentiment of the public in line with the main research questions, emotion detection was also performed. In particular, the emotion analysis was based on Plutchik's wheel of emotions which presents eight (8) basic emotions which come in pairs and the opposite emotions cannot be felt simultaneously (Plutchik and Kellerman, 1980; Plutchik, 1984). The emotions along with their pairings are: joy and sadness, acceptance and disgust, fear and anger as well as surprise and anticipation. Furthermore, the latest National Research Council Canada (NRC) Word-Emotion Association Lexicon (EmoLex) (Mohammad and Turney, 2010; Mohammad and Turney, 2013; Mohammad, 2020) was used as a basis for the lexiconbased sentiment analysis for emotion detection. The NRC emotion lexicon constitutes a list of English words along with their associations with the eight (8) basic emotions and two (2) sentiments.

\section{Tools used}

The whole code and all scripts developed for the purposes of fulfilling this task were based on the Python programming language (version 3.8) which is an interpreted, object-oriented, high-level programming language with dynamic semantics. PyCharm was selected as the open-source integrated development environment (IDE). Additionally, in order to retrieve the related data, in our case tweets, the Twitter API was used. With a view to increasing the overall usability, flexibility and extensibility, the retrieved data was stored in both CSV and JSON files. For the purposes of data visualization, the open-source python library Matplotlib was used (Hunter, 2007). Finally, both TextBlob and EmoLex, which were presented earlier, were used to conduct sentiment analysis.

Developing a new machine learning model to conduct sentiment analysis was outside the scope of this specific study. For that reason and as above mentioned regarding the sentiment analysis, TextBlob and VADER were selected for the polarity detection while EmoLex was used in order to conduct emotion detection. It is worth noting that all the tools and libraries used for this study are open-source.

As TextBlob is rule-based, a pre-defined set of categorized words is required. For the purposes of this study, the widely used, verified and accepted Natural Language Toolkit 
(NLTK) database was used which contains a dictionary of words and their respective sentiment scores. Additionally, for each polarity task TextBlob provides a float within the range of $[-1.0,1.0]$ with -1.0 meaning a negative polarity, 1.0 a positive one while 0 refers to a neutral state. Several other studies such as (Ahuja and Dubey, 2017; Saha et al., 2017; Manguri et al., 2020) have also used TextBlob to successfully carry out sentiment analysis for Twitter data. To further evaluate and verify the results, VADER which is both a lexicon and a rule-based analysis tool was used. VADER, which is particularly useful for carrying out sentiment analysis on social media data, contains labeled lexical features based on their semantic orientation and utilizes them in order to calculate the text sentiment. Based on these, it calculates the probability of a given sentence, in our case tweet, to be either positive, negative or neutral. Several studies such as (Ramteke et al., 2016; Park and Seo, 2018; Elbagir and Yang, 2019) utilized this open-source tool to conduct similar analyses. Furthermore, as the emotion analysis is based on the eight basic emotions presented in Plutchik's wheel of emotions, EmoLex was selected. In particular, the EmoLex lexicon constitutes a list of words along with their associations with the eight (8) basic emotions and two (2) sentiments. Due to its vast usability and popularity, it has been translated into more than one hundred languages. Through the studies that have utilized it, it has been showcased that a majority of affective norms remain stable across languages. Various studies such as van den Broek-Altenburg and Atherly (2019), Corazza et al. (2020) and Mathur et al. (2020) have used EmoLex as a tool to conduct sentiment analysis using tweets. In all cases, the sentiments and emotions are calculated based on the frequency of words in each sentence as well as the semantic relations. Consequently, more precise and accurate results are generated.

\section{Results}

With a view to answering our main research questions and understanding the crowd wisdom on these specific matters, the above-mentioned methodology was used and two separate data sets containing Twitter data which was retrieved from January 2010 to December 2020 were created. The first data set contained a total of 691,714 data entries (tweets) regarding the public's viewpoints and attitudes towards $360^{\circ}$ video while the second one consisted of 4721 data entries concerning the public's viewpoints on the use of $360^{\circ}$ video in education. Our analysis results include tables, figures, graphs, word clouds, plots and diagrams. The information of both data sets was examined (1) as a whole and (2) on an annual basis. Particularly, the most frequently used words (with and without keywords), hashtags and mentions in the relevant tweets were analyzed. Additionally, the number of tweets made per each year and month as well as the countries that tweeted the most about the relevant topics were analyzed. Finally, polarity and emotion detection sentiment analyses were carried out.

\section{General use of $360^{\circ}$ video}

The results regarding the public's opinion on $360^{\circ}$ video from January 2010 to December 2020 are presented below:

Word frequency analysis with keywords: The top-40 most commonly used words including keywords are displayed on Table 1 from which the top- 5 words were: video, 360 , virtual reality (vr), 360-degree and 360-video. 
Table 1 Frequency of the top-40 most commonly used words within the tweets including keywords in the years of 2010-2020

\begin{tabular}{llllllll}
\hline Word & Frequency & Word & Frequency & Word & Frequency & Word & Frequency \\
\hline video & 641,725 & via & 50,166 & reality & 19,387 & tour & 13,980 \\
360 & 433,636 & degree & 48,154 & check & 19,317 & immersive & 13,520 \\
virtualreality (vr) & 120,070 & facebook & 40,478 & news & 18899 & app & 13,313 \\
360-degree & 117,838 & live & 37,176 & $4 \mathrm{k}$ & 18,328 & look & 13,082 \\
360video & 109,505 & like & 33,350 & liked & 18,261 & show & 12,536 \\
xbox & 101,836 & camera & 31,846 & see & 16,763 & tech & 12,240 \\
youtube & 93,930 & watch & 28,873 & work & 15,909 & set & 12,073 \\
game & 83,777 & experience & 23,869 & get & 14,925 & marketing & 11,925 \\
$360^{\circ}$ & 77,713 & virtual & 22,619 & take & 14,716 & complete & 11,722 \\
new & 53,956 & first & 21,573 & launch & 14,546 & amazing & 11,383 \\
\hline
\end{tabular}

Table 2 Frequency of the top-40 most commonly used words within the tweets excluding keywords in the years of 2010-2020

\begin{tabular}{|c|c|c|c|c|c|c|c|}
\hline Word & Frequency & Word & Frequency & Word & Frequency & Word & Frequency \\
\hline virtualreality (vr) & 120,070 & watch & 28,873 & get & 14,925 & marketing & 11,925 \\
\hline xbox & 101,836 & experience & 23,869 & take & 14,716 & complete & 11,722 \\
\hline youtube & 93,930 & virtual & 22,619 & launch & 14,546 & amazing & 11,383 \\
\hline game & 83,777 & first & 21,573 & tour & 13,980 & twitter & 10,974 \\
\hline new & 53,956 & reality & 19,387 & immersive & 13,520 & $3 d$ & 10,940 \\
\hline via & 50,166 & check & 19,317 & app & 13,313 & support & 10,617 \\
\hline facebook & 40,478 & news & 18,899 & look & 13,082 & one & 10,601 \\
\hline live & 37,176 & $4 \mathrm{k}$ & 18,328 & show & 12,536 & make & 10,437 \\
\hline like & 33,350 & see & 16,763 & tech & 12,240 & use & 10,377 \\
\hline camera & 31,846 & work & 15,909 & set & 12,073 & microsoft & 10,250 \\
\hline
\end{tabular}

Word frequency analysis without keywords: The top-5 most commonly used words excluding keywords were: virtualreality (vr), xbox, youtube, game and new. The results of the top- 40 most commonly used words excluding keywords are displayed on Table 2.

Hashtag frequency analysis: The top- 40 most commonly used hashtags are presented in Table 3 from which the top-5 were: \#360video, \#VR, \#360Video, \#VirtualReality and \#360.

Mention frequency analysis: The top- 4 most commonly used magazine, manufacturer and social media mentions for each year are displayed on Table 4.

Frequency of tweets over the period of 2010-2020: the frequency of the monthly and annual tweets over the years 2010-2020 are presented in Table 5 .

Country frequency analysis: As users are free to set the details about the country private, which is also the default option in Twitter, it is not possible to retrieve this specific information from all users. More details about this issue will be provided in the challenges and limitations subsection further below. For that reason and although it might not be completely representative of the whole data set, the top- 5 countries that tweeted the most based on the country data that we managed to collect were: the United States, India, Japan, Canada, and Australia. 
Table 3 Frequency of the top-40 most commonly used hashtags within the tweets in the years of 2010-2020

\begin{tabular}{llllllll}
\hline Hashtag & Freq. & Hashtag & Freq. & Hashtag & Freq. & Hashtag & Freq. \\
\hline \#360video & 83,179 & \#vr & 9139 & \#Xbox & 3497 & \#Photography & 2356 \\
\#VR & 57,657 & \#video & 9131 & \#immersive & 3396 & \#360camera & 2208 \\
\#360Video & 26,413 & \#4K & 7875 & \#socialmedia & 3391 & \#SocialMedia & 2159 \\
\#VirtualReality & 20,267 & \#virtualreality & 7244 & \#Facebook & 3369 & \#VR360 & 2140 \\
\#360 & 11,416 & \#Video & 7188 & \#Game & 3001 & \#theta360 & 2124 \\
\#Beautiful & 9312 & \#tech & 6023 & \#YouTube & 2926 & \#Welcome & 1990 \\
\#Ocean & 9312 & \#AR & 5639 & \#VRvideo & 2828 & \#Tech & 1954 \\
\#Scubadiving & 9297 & \#technology & 4476 & \#marketing & 2659 & \#photography & 1926 \\
\#EuMIVR & 9296 & \#VRVideo & 3581 & \#360vr & 2558 & \#art & 1919 \\
\#EuMI & 9296 & \#3D & 3570 & \#news & 2546 & \#GoogleDoodle & 1903 \\
\hline
\end{tabular}

Table 4 Frequency of the most mentioned social media platforms, magazines and manufacturers throughout the years of 2010-2020

\begin{tabular}{lllllllllllll}
\hline & $\mathbf{2 0 1 0}$ & $\mathbf{2 0 1 1}$ & $\mathbf{2 0 1 2}$ & $\mathbf{2 0 1 3}$ & $\mathbf{2 0 1 4}$ & $\mathbf{2 0 1 5}$ & $\mathbf{2 0 1 6}$ & $\mathbf{2 0 1 7}$ & $\mathbf{2 0 1 8}$ & $\mathbf{2 0 1 9}$ & $\mathbf{2 0 2 0}$ & Total \\
\hline $\begin{array}{l}\text { Social media platforms } \\
\text { @YouTube }\end{array}$ & 24 & 189 & 384 & 367 & 433 & 10,123 & 21,665 & 14,206 & 10,669 & 2020 & 1470 & 61,550 \\
@Facebook & 2 & 0 & 0 & 0 & 1 & 307 & 426 & 188 & 29 & 9 & 3 & 965 \\
@Twitter & 0 & 0 & 0 & 0 & 0 & 6 & 168 & 111 & 6 & 3 & 2 & 299 \\
@Vimeo & 1 & 0 & 1 & 0 & 3 & 44 & 54 & 172 & 11 & 7 & 2 & 295 \\
@Linkedln & 0 & 0 & 0 & 1 & 0 & 38 & 68 & 43 & 1 & 2 & 2 & 155 \\
@instagram & 0 & 0 & 0 & 0 & 0 & 1 & 21 & 10 & 9 & 3 & 0 & 44 \\
Magazines & & & & & & & & & & & & \\
@TechCrunch & 0 & 3 & 62 & 1 & 4 & 252 & 744 & 232 & 43 & 3 & 0 & 1344 \\
@nytimes & 0 & 0 & 0 & 0 & 1 & 31 & 259 & 477 & 65 & 6 & 6 & 845 \\
@WIRED & 0 & 0 & 0 & 2 & 0 & 182 & 176 & 107 & 8 & 5 & 6 & 485 \\
@USATODAY & 0 & 0 & 0 & 3 & 0 & 161 & 173 & 36 & 7 & 1 & 0 & 381 \\
Manufacturers & & & & & & & & & & & & \\
@VuzeCamera & 0 & 0 & 0 & 0 & 0 & 1 & 47 & 640 & 491 & 32 & 5 & 1216 \\
@GoPro & 0 & 0 & 3 & 137 & 73 & 230 & 244 & 106 & 105 & 85 & 80 & 1063 \\
@insta360 & 0 & 0 & 0 & 0 & 0 & 1 & 46 & 209 & 188 & 183 & 129 & 756 \\
@oculus & 0 & 0 & 0 & 6 & 32 & 69 & 67 & 40 & 57 & 41 & 25 & 337 \\
\hline
\end{tabular}

Sentiment analysis-polarity detection: According to the polarity detection, the majority of the tweets was neutral (46.5\%) followed by positive $(39.4 \%)$ while only $14.1 \%$ of the tweets was negative when using TextBlob while $53.72 \%$ neutral, $37.2 \%$ positive and $9.08 \%$ negative when utilizing VADER. The related results for each year are presented in Table 6 .

Sentiment analysis-emotion detection: According to the analysis, the emotion frequency based on the most intense emotion of each tweet was: $53.39 \%$ Neutral (369,304 tweets), Anticipation 18.58\% (128,505 tweets), Trust 7.55\% (52,240 tweets), Anger 6.75\% (46,703 tweets), Joy 5.59\% (38,686 tweets), Fear 4.17\% (28,818 tweets), Sadness $2.12 \%$ (14,641 tweets), Surprise 1.09\% (7520 tweets) and the related results for each year are depicted on Table 7. 
Table 5 Monthly and annual tweets over the years 2010-2020

\begin{tabular}{llllllllllll}
\hline & $\mathbf{2 0 1 0}$ & $\mathbf{2 0 1 1}$ & $\mathbf{2 0 1 2}$ & $\mathbf{2 0 1 3}$ & $\mathbf{2 0 1 4}$ & $\mathbf{2 0 1 5}$ & $\mathbf{2 0 1 6}$ & $\mathbf{2 0 1 7}$ & $\mathbf{2 0 1 8}$ & $\mathbf{2 0 1 9}$ & $\mathbf{2 0 2 0}$ \\
\hline January & 2357 & 3753 & 2085 & 967 & 1575 & 2701 & 12,192 & 15,401 & 6171 & 3756 & 2152 \\
February & 1043 & 1528 & 1406 & 844 & 3420 & 1194 & 19,384 & 11,951 & 7625 & 2863 & 2078 \\
March & 1456 & 1409 & 1868 & 965 & 3303 & 6529 & 17,753 & 15,365 & 6607 & 3356 & 2321 \\
April & 1550 & 2185 & 2341 & 870 & 3930 & 1472 & 31,382 & 17,818 & 5220 & 3311 & 2100 \\
May & 1468 & 2058 & 1081 & 1748 & 1617 & 3197 & 21,446 & 12,442 & 7352 & 2773 & 2068 \\
June & 1877 & 2559 & 1479 & 897 & 1398 & 7812 & 22,833 & 9999 & 4905 & 2558 & 2174 \\
July & 1144 & 1615 & 1187 & 1010 & 2441 & 10,007 & 17,724 & 10,093 & 5962 & 2551 & 2031 \\
August & 1077 & 1313 & 1012 & 1492 & 1405 & 5803 & 20,465 & 9747 & 4772 & 2651 & 2010 \\
September & 923 & 1547 & 903 & 2123 & 1721 & 18,110 & 13,685 & 8321 & 4498 & 2395 & 1845 \\
October & 2348 & 2019 & 917 & 1921 & 4498 & 10,338 & 15,088 & 9061 & 4226 & 2609 & 1966 \\
November & 1531 & 1705 & 2802 & 2097 & 2269 & 11,567 & 16,799 & 8524 & 4371 & 2464 & 1538 \\
December & 1402 & 1658 & 3581 & 2241 & 2487 & 13,168 & 22,875 & 7450 & 3495 & 2272 & 1546 \\
Total & 18,176 & 23,349 & 20,662 & 17,175 & 30,064 & 91,898 & 231,626 & 136,172 & 65,204 & 33,559 & 23,829 \\
\hline
\end{tabular}

Table 6 The polarity frequency of the tweets over the years 2010-2020

\begin{tabular}{lllllllllllll}
\hline & $\mathbf{2 0 1 0}$ & $\mathbf{2 0 1 1}$ & $\mathbf{2 0 1 2}$ & $\mathbf{2 0 1 3}$ & $\mathbf{2 0 1 4}$ & $\mathbf{2 0 1 5}$ & $\mathbf{2 0 1 6}$ & $\mathbf{2 0 1 7}$ & $\mathbf{2 0 1 8}$ & $\mathbf{2 0 1 9}$ & $\mathbf{2 0 2 0}$ & Total \\
\hline Using TextBlob & & & & & & & & & & & \\
Positive & 6301 & 6910 & 5934 & 3797 & 9984 & 38,516 & 88,959 & 60,158 & 28,726 & 13,747 & 9527 & 272,559 \\
Negative & 6888 & 8596 & 4980 & 8722 & 10,989 & 7426 & 29,815 & 10,681 & 4718 & 2716 & 2182 & 97,510 \\
Neutral & 5187 & 7843 & 9748 & 4656 & 9091 & 45,959 & 112,852 & 65,333 & 31,760 & 17,096 & 12,120 & 321,645 \\
Using VADER & & & & & & & & & & & \\
Positive & 7380 & 7823 & 6722 & 5006 & 8068 & 35,435 & 77,865 & 51,210 & 28,556 & 17,095 & 12,151 & 257,311 \\
Negative & 2535 & 3573 & 2502 & 2355 & 3527 & 8637 & 20,154 & 10,454 & 4654 & 2634 & 1774 & 62,799 \\
Neutral & 8261 & 11,953 & 11,438 & 9814 & 18,469 & 47,826 & 133,607 & 74,508 & 31,994 & 13,830 & 9904 & 371,604
\end{tabular}

\section{Use of $360^{\circ}$ video in education}

Based on the keywords used, a total of 4721 tweets were collected. As we wanted to eliminate the chance that the content of a tweet related only to a specific $360^{\circ}$ video, meaning that the users' sentiment will be based on the content of the video and not on the technology itself, we manually applied more filters. As a result, a total of 3,241 tweets were used for the data analysis. The results regarding the public's opinion on $360^{\circ}$ video in education from January 2010 to December 2020 are:

Word frequency analysis with keywords: The top-5 most commonly used words including keywords were: video, 360, education, virtualreality (vr) and school. The results of the top-40 most commonly used words are displayed on Table 8.

Word frequency analysis without keywords: The top- 40 most commonly used words excluding keywords are presented in Table 9 from which the top- 5 were: virtualreality (vr), youtube, reality, weekly and technology.

Hashtag frequency analysis: The top- 40 most commonly used hashtags are displayed on Table 10 from which the top-5 were: \#360video, \#education, \#VR, \#technology and \#immersive.

Frequency of tweets over the period of 2010-2020: The frequency of the monthly and annual tweets over the years 2010-2020 are presented in Table 11. 
Table 7 Emotion frequency based on the most intense emotion of each tweet for each year over the years 2010-2020

\begin{tabular}{llllllllll}
\hline & Joy & Trust & Fear & Surprise & Sadness & Disgust & Anger & Anticipation & Neutral \\
\hline 2010 & 790 & 1407 & 676 & 199 & 874 & 172 & 1753 & 2910 & 9395 \\
2011 & 975 & 1302 & 1044 & 247 & 873 & 186 & 2718 & 3685 & 12,319 \\
2012 & 749 & 1694 & 789 & 230 & 484 & 103 & 1505 & 3926 & 11,182 \\
2013 & 425 & 777 & 1004 & 161 & 686 & 219 & 1861 & 2458 & 9584 \\
2014 & 1355 & 1882 & 1746 & 172 & 848 & 245 & 3021 & 3669 & 17,126 \\
2015 & 8877 & 4900 & 4307 & 624 & 1827 & 377 & 5760 & 15,575 & 49,651 \\
2016 & 10,820 & 17,397 & 9908 & 2672 & 5177 & 1833 & 13,738 & 45,237 & 124,844 \\
2017 & 6778 & 9997 & 4674 & 1428 & 1866 & 1056 & 9497 & 29,271 & 71,605 \\
2018 & 3682 & 7603 & 2590 & 1046 & 1129 & 543 & 4238 & 11,641 & 32,732 \\
2019 & 2459 & 2976 & 1315 & 424 & 511 & 287 & 1531 & 6158 & 17,898 \\
2020 & 1776 & 2305 & 765 & 317 & 366 & 276 & 1081 & 3975 & 12,968 \\
Total & 38,686 & 52,240 & 28,818 & 7520 & 14,641 & 5297 & 46,703 & 128,505 & 369,304 \\
\hline
\end{tabular}

Table 8 Frequency of the top-40 most commonly used words within the tweets including keywords in the years of 2010-2020

\begin{tabular}{llllllll}
\hline Word & Freq. & Word & Freq. & Word & Freq. & Word & Freq. \\
\hline video & 2423 & immersive & 434 & educationtech & 302 & spotlight & 228 \\
360 & 1860 & youtube & 406 & 360 -degree & 301 & releases & 222 \\
education & 1336 & story & 331 & shortfilmsubscribe & 301 & bbc & 212 \\
virtualreality (vr) & 1,305 & travel & 314 & newsletter & 300 & spainindie & 182 \\
school & 1057 & entertainment & 313 & virtual & 286 & new & 172 \\
360video & 1007 & 360camera & 310 & $360^{\circ}$ & 270 & excited & 160 \\
university & 534 & vlog & 307 & via & 266 & classtechtips & 160 \\
reality & 523 & 360photo & 305 & edtech & 252 & degree & 159 \\
weekly & 493 & nutshell & 303 & student & 245 & film & 149 \\
technology & 441 & photooftheday & 303 & creator & 233 & high & 146 \\
\hline
\end{tabular}

Table 9 Frequency of the top-40 most commonly used words within the tweets excluding keywords in the years of 2010-2020

\begin{tabular}{llllllll}
\hline Word & Freq. & Word & Freq. & Word & Freq. & Word & Freq. \\
\hline virtualreality (vr) & 1305 & vlog & 307 & student & 245 & high & 146 \\
youtube & 555 & 360photo & 305 & creator & 233 & check & 131 \\
reality & 523 & nutshell & 303 & spotlight & 228 & take & 124 \\
weekly & 493 & photooftheday & 303 & releases & 222 & learn & 123 \\
technology & 441 & educationtech & 302 & bbc & 212 & news & 116 \\
immersive & 434 & shortfilmsubscribe & 301 & spainindie & 182 & experience & 110 \\
story & 331 & newsletter & 300 & new & 172 & tour & 109 \\
travel & 314 & virtual & 286 & excited & 160 & watch & 101 \\
entertainment & 313 & via & 266 & classtechtips & 160 & $3 d$ & 100 \\
360camera & 310 & edtech & 252 & film & 149 & camera & 98 \\
\hline
\end{tabular}

Country frequency analysis: As mentioned above, due to the limitation that the country field is a private one, the results of this category might not fully represent the entire data set. Nevertheless, based on the collected data, the top-5 countries that tweeted the most 
Table 10 Frequency of the top-40 most commonly used hashtags within the Tweets in the years of 2010-2020

\begin{tabular}{llllllll}
\hline Hashtag & Freq. & Hashtag & Freq. & Hashtag & Freq. & Hashtag & Freq. \\
\hline \#360video & 859 & \#entertainment & 305 & \#Education & 102 & \#VRstudio & 48 \\
\#education & 655 & \#360photo & 305 & \#vr & 96 & \#VRcompany & 47 \\
\#VR & 406 & \#Travel & 303 & \#3D & 61 & \#WhiteHouse & 47 \\
\#technology & 390 & \#photooftheday & 303 & \#VRheadset & 59 & \#youtube & 45 \\
\#immersive & 375 & \#shortfilmSUB. & 301 & \#360 & 58 & \#entrepreneur & 44 \\
\#tech & 336 & \#newsletter & 295 & \#VRexperience & 56 & \#code & 44 \\
\#XR & 309 & \#edtech & 235 & \#Creative & 54 & \#twitchtv & 43 \\
\#360camera & 309 & \#virtualreality & 203 & \#AR & 52 & \#unity3d & 43 \\
\#VirtualReality & 306 & \#Spainlndie & 172 & \#VRvideo & 52 & \#VRpainting & 43 \\
\#vlog & 306 & \#360Video & 162 & \#VRnews & 49 & \#gamer & 43 \\
\hline
\end{tabular}

Table 11 Monthly and annual tweets over the years 2010-2020

\begin{tabular}{llllllllllll}
\hline & $\mathbf{2 0 1 0}$ & $\mathbf{2 0 1 1}$ & $\mathbf{2 0 1 2}$ & $\mathbf{2 0 1 3}$ & $\mathbf{2 0 1 4}$ & $\mathbf{2 0 1 5}$ & $\mathbf{2 0 1 6}$ & $\mathbf{2 0 1 7}$ & $\mathbf{2 0 1 8}$ & $\mathbf{2 0 1 9}$ & $\mathbf{2 0 2 0}$ \\
\hline January & 0 & 2 & 1 & 5 & 1 & 2 & 19 & 106 & 41 & 38 & 89 \\
February & 0 & 7 & 0 & 0 & 3 & 1 & 87 & 42 & 58 & 38 & 92 \\
March & 1 & 0 & 2 & 0 & 0 & 2 & 40 & 66 & 62 & 26 & 29 \\
April & 0 & 0 & 1 & 1 & 7 & 4 & 32 & 105 & 41 & 38 & 6 \\
May & 1 & 7 & 5 & 0 & 0 & 7 & 150 & 54 & 70 & 26 & 34 \\
June & 2 & 7 & 2 & 1 & 0 & 5 & 76 & 48 & 58 & 35 & 40 \\
July & 7 & 3 & 2 & 4 & 3 & 12 & 32 & 36 & 69 & 27 & 21 \\
August & 0 & 5 & 1 & 0 & 2 & 11 & 46 & 47 & 47 & 21 & 33 \\
September & 0 & 0 & 1 & 0 & 2 & 13 & 53 & 69 & 54 & 27 & 17 \\
October & 66 & 1 & 0 & 0 & 12 & 7 & 30 & 120 & 52 & 33 & 19 \\
November & 5 & 0 & 0 & 0 & 3 & 12 & 42 & 55 & 29 & 98 & 20 \\
December & 1 & 2 & 0 & 0 & 2 & 11 & 37 & 74 & 33 & 79 & 10 \\
Total & 83 & 34 & 15 & 11 & 35 & 87 & 644 & 822 & 614 & 486 & 410
\end{tabular}

about the educational use of $360^{\circ}$ video were: Spain, the United States, Canada, Australia and India.

Sentiment Analysis-Polarity Detection: Based on the results of the polarity detection, the majority of the tweets was neutral (54.3\%) followed by positive (39.68\%) while only $6.02 \%$ of the tweets was negative when using TextBlob while $47.24 \%$ positive, $46.65 \%$ neutral and 6.11\% negative when utilizing VADER. The related annual results are depicted on Table 12.

Sentiment analysis-emotion detection: According to the analysis, the emotion frequency based on the most intense emotion of each tweet was: Neutral 30.39\% (985 tweets), Trust 29.96\% (971 tweets), Anticipation 25.52\% (827 tweets), Joy 4.6\% (149 tweets), Surprise 3.3\% (107 tweets), Anger 2.68\% (87 tweets), Fear 2.41\% (78 tweets), Sadness $0.62 \%$ (20 tweets) and Disgust $0.52 \%$ (17 tweets) and the related results for each year are presented in Table 13.

\section{Discussion}

The aim of the present study was to comprehend the general public's viewpoints and attitudes towards $360^{\circ}$ video overall while also putting emphasis on the application of $360^{\circ}$ video in education. With a view to providing a more complete overview and 
Table 12 The polarity frequency of the tweets over the years 2010-2020

\begin{tabular}{lllllllllllll}
\hline & $\mathbf{2 0 1 0}$ & $\mathbf{2 0 1 1}$ & $\mathbf{2 0 1 2}$ & $\mathbf{2 0 1 3}$ & $\mathbf{2 0 1 4}$ & $\mathbf{2 0 1 5}$ & $\mathbf{2 0 1 6}$ & $\mathbf{2 0 1 7}$ & $\mathbf{2 0 1 8}$ & $\mathbf{2 0 1 9}$ & $\mathbf{2 0 2 0}$ & Total \\
\hline $\begin{array}{l}\text { Using TextBlob } \\
\text { Positive }\end{array} 11$ & 18 & 8 & 5 & 23 & 37 & 198 & 323 & 345 & 196 & 122 & 1286 \\
Negative & 10 & 9 & 1 & 3 & 3 & 4 & 61 & 19 & 32 & 14 & 39 & 195 \\
Neutral & 62 & 7 & 6 & 3 & 9 & 46 & 385 & 480 & 237 & 276 & 249 & 1760 \\
Using VADER & & & & & & & & & & & \\
Positive & 5 & 23 & 6 & 5 & 12 & 43 & 210 & 267 & 318 & 343 & 299 & 1531 \\
Negative & 68 & 0 & 0 & 0 & 6 & 4 & 36 & 31 & 23 & 15 & 15 & 198 \\
Neutral & 10 & 11 & 9 & 6 & 17 & 40 & 398 & 524 & 273 & 128 & 96 & 1512 \\
\hline
\end{tabular}

Table 13 Emotion frequency based on the most intense emotion of each tweet for each year over the years 2010-2020

\begin{tabular}{llllllllll}
\hline & Joy & Trust & Fear & Surprise & Sadness & Disgust & Anger & Anticipation & Neutral \\
\hline 2010 & 0 & 67 & 7 & 0 & 0 & 0 & 0 & 4 & 5 \\
2011 & 1 & 19 & 0 & 0 & 0 & 0 & 0 & 14 & 0 \\
2012 & 0 & 9 & 0 & 0 & 0 & 0 & 0 & 3 & 3 \\
2013 & 0 & 8 & 0 & 0 & 0 & 0 & 0 & 0 & 3 \\
2014 & 2 & 15 & 1 & 0 & 0 & 0 & 6 & 5 & 6 \\
2015 & 6 & 36 & 0 & 0 & 0 & 0 & 1 & 14 & 30 \\
2016 & 22 & 195 & 19 & 8 & 4 & 10 & 24 & 220 & 142 \\
2017 & 24 & 261 & 9 & 66 & 2 & 1 & 19 & 210 & 230 \\
2018 & 49 & 169 & 23 & 26 & 2 & 2 & 16 & 184 & 143 \\
2019 & 34 & 83 & 11 & 2 & 3 & 3 & 15 & 105 & 230 \\
2020 & 11 & 109 & 8 & 5 & 9 & 1 & 6 & 68 & 193 \\
Total & 149 & 971 & 78 & 107 & 20 & 17 & 87 & 827 & 985 \\
\hline
\end{tabular}

a clearer depiction of the public's opinions regarding $360^{\circ}$ video, the study examined the related data of the last decade. This time period was selected as several advancements have been accomplished and the specific technology has been more accessible and more widely used.

Based on the results, an increasing interest in $360^{\circ}$ video was noticed in September 2015 and afterwards and more specifically on 23/9/2015 when Facebook introduced $360^{\circ}$ video on their platform. The highest number of tweets was observed during December 2016 and particularly on 28/12/2016 when $360^{\circ}$ video was also introduced on Twitter. Moreover, it was observed that $360^{\circ}$ video is highly associated with social media, immersive experiences and contemporary technologies such as virtual reality and $4 \mathrm{k}$ videos. YouTube was by far the most mentioned account within the tweets. Additionally, in both cases the analysis also revealed that there were tweets about $360^{\circ}$ video from all five continents, suggesting a worldwide spread of its use.

Regarding the general use of $360^{\circ}$ video, the results of the social media data analysis suggested that $360^{\circ}$ video is used worldwide and positive emotions, such as anticipation and trust, are associated with it. The majority of the activities related to $360^{\circ}$ video were recreational (e.g., gaming, scuba diving) and YouTube was the most popular social media platform used to present $360^{\circ}$ video. Moreover, based on the polarity 
analysis, the majority of people were either positive or neutral about the use of $360^{\circ}$ video with only a very small number being negative. Therefore, it can be said that the majority of people found $360^{\circ}$ video as a useful daily tool.

The results concerning the use of $360^{\circ}$ in education showed that the majority of people positively viewed $360^{\circ}$ video as an educational tool. Based on the emotion detection, $360^{\circ}$ video was considered to be intriguing and useful for educational purposes as people expressed joy, anticipation and trust when referring to it. Once again, YouTube was the most mentioned social media platform. This fact demonstrates its popularity for educational purposes. Furthermore, words and hashtags relevant to immersion were widely associated with the use of $360^{\circ}$ video in education which reinforces the aspect that $360^{\circ}$ video can be used in conjunction with immersive technologies such as augmented reality and virtual reality to create more interactive, fun and engaging experiences.

At this stage, it should be said that although there is a small difference between the results of the two tools used to conduct sentiment analysis caused by their using different sentiment scores, the majority of the sentiments followed the exact same order in both cases. This fact further validates the method, tools and results of this study.

Overall, this study in line with previous research evidence demonstrated that the public has a positive view and attitude towards $360^{\circ}$ video in everyday life and in education. Furthermore, the results of previous studies suggest that students rated high in satisfaction and immersiveness lessons that had incorporated $360^{\circ}$ video and reported positive attitudes (Harrington et al., 2018; Hodgson et al., 2019; Liu et al., 2010). Therefore, it can be said that the results of the sentiment analysis seem to also reflect students' learning experiences when $360^{\circ}$ video was used as an educational tool.

Similar to traditional teaching, $360^{\circ}$ video can assist in improving students' comprehensibility, promote their active participation, creativity and engagement (Coller and Shernoff, 2009) and increase their concentration and enjoyment, fostering thus optimal learning conditions (Shernoff et al., 2014). However, $360^{\circ}$ video provides a higher level of interactivity and immersiveness which is essential for the educational process to be effective (Zhang et al., 2006). This type of interactivity in combination with higher levels of satisfaction experienced in lessons that incorporate $360^{\circ}$ video is expected to increase students' engagement in the class. Engagement is a prime contributor to learning, teaching and academic success (Appleton et al., 2006; Fredricks et al., 2004; Wang and Holcombe, 2010). Therefore, creating immersive and interactive experiences through $360^{\circ}$ video that promotes students' active participation and engagement is of great significance. Consequently, interactive design approaches which increase the positive aspects of the user experience and decrease the negative ones should be adopted (Preece et al., 2015) as they will increase students' development and academic performance in the long run. Thus, the effective use of $360^{\circ}$ video can constitute an alternative method of learning and teaching as it offers an immersive experience and seems to be more attractive to and favorably received by students (Huang et al., 2010; Olmos et al., 2018).

Concerning education, which is the focus of the present study, students are able to comprehend abstract concepts more easily within interactive three-dimensional (3D) virtual environments (Fernandez, 2017). As mentioned above and as our results showcased, there is a close relationship between virtual reality and $360^{\circ}$ video. When these technologies are combined, immersive experiences that could further enhance the 
positive learning outcomes could be developed. Particularly, virtual reality enables users to be immersed in virtual environments and as a result, it reinforces students' feeling of immersion and engagement by allowing them to interact and communicate with the virtual world and its contents (Berns et al., 2018) while also inducing their emotions (Riva et al., 2007). Virtual reality is regarded as an appropriate for pedagogical purposes technology (Mikropoulos and Natsis, 2011). Therefore, $360^{\circ}$ video can capitalize on the numerous educational benefits that virtual reality offers (Merchant et al., 2014), such as real-time feedback (Sherman and Craig, 2018) and opportunities to practice professional skills (Hodgson et al., 2019).

Finally, it is worth noting that a large number of social media tweets were neutral. Thus, it can be inferred that the general public are either unaware of the benefits of using $360^{\circ}$ video in the educational process. As we cannot be certain about the occupation of the people who tweeted, we could speculate that in the case of educators a lack of technical skills or of the appropriate equipment and experience to develop educational material based on $360^{\circ}$ video could be another reason. All in all, the usefulness and effectiveness of $360^{\circ}$ video as educational tools should be further promoted by educational authorities and policy makers in order to integrate it into existing curricula and secure resources for the development of educational $360^{\circ}$ video as it can constitute an invaluable educational tool that can be applied in all levels of education.

\section{Challenges and limitations}

Despite the specific methodology being widely used in analyzing social media data as it has been showcased in earlier sections, there still remain some challenges and limitations. The main challenges in our study were (a) defining the most suitable time period during which the text retrieval should be carried out and data should be analyzed, (b) selecting the most effective social media platform which would generate the most accurate data and (c) overcoming the various limitations that the official Twitter API sets. Additionally, with a view to providing more cohesive results, some limitations were set such as limiting the text mining to tweets that were written in English.

Nonetheless, there are some inherent limitations. Due to privacy and security manners, several data fields are regarded as private personal data in Twitter and cannot be retrieved unless made publicly available by the user. This is the case for the field of occupation. For that reason and although it would be particularly constructive, retrieving, identifying and distinguishing the occupation of each person who tweeted was not feasible. As mentioned above, the same applies for the country field. Even though some of the tweets contained this information and despite the fact that the data was normalized later, we do not believe it reflects the actual numbers and therefore, only the top- 5 most common countries for each data set were mentioned.

Finally, although the specific methodology and tools used allowed for the retrieval of social media posts that solely contained text regarding $360^{\circ}$ video, there are still some limitations regarding their sentiment analysis. In particular, as this analysis method examines the text of each post, it could be possible that in some cases the concluded sentiment and emotion were a result of the specific content of a video and not of the technology in itself. Even though this is a common phenomenon in similar studies, we tried to limit its impact by manually filtering the retrieved data to include 
only the data directly related to the technology of $360^{\circ}$ video in education in the case of the educational data set.

\section{Conclusions}

The technology of 360-degree video is becoming more and more popular. As previous studies showcased, $360^{\circ}$ video increases immersiveness and can be applied in various domains and use cases. Moreover, emphasis is being put on the education field, as $360^{\circ}$ video can help satisfy the new and upcoming educational needs. However, so far, we have had no evidence on the informal evaluation of $360^{\circ}$ video from people using it in their everyday life and in education. This study analyzed the results of the last decade regarding the public's viewpoints and attitudes towards $360^{\circ}$ video and its use in educational settings and its results are in line with those of previous studies. Particularly, this study highlighted that the public perceive $360^{\circ}$ video in a positive manner while mostly expressing anticipation, trust and joy when referring to it. Nonetheless, the majority of teachers of all educational levels might not yet be familiar with $360^{\circ}$ video or have the necessary technical skills or equipment to develop educational material using it or incorporating it into their teaching activities. Therefore, efforts should be made to inform the educational community about the benefits of using this learning approach and how to integrate it into the existing teaching curricula. According to existing evidence and public viewpoints and attitudes identified in the present study, $360^{\circ}$ video can constitute an invaluable educational tool which can boost academic performance.

To sum up, due to the auditory and visual immersion $360^{\circ}$ video offers, it may help satisfy students' emerging needs and meet the new educational requirements successfully and thus resulting in more effective learning. Particularly, $360^{\circ}$ video can be regarded as a useful means that creates richer virtual experiences and as a complementary educational tool that can enrich the teaching and learning process as well as promote and enhance students' motivation, engagement and enjoyment. Due to its interconnected nature, $360^{\circ}$ video can be used in conjunction with several other technologies such as virtual reality and augmented reality as well as with innovative learning approaches and methods e.g. gamification, flipped classroom, digital story telling etc. to provide several educational benefits and improve the overall learning and teaching process. Therefore, it may play a vital role in education in the near future. Finally, to better assess the effectiveness of $360^{\circ}$ video in education, future studies should highlight the role of educators, teachers and students and involve them in the development process in an active way so as to create more personalized and student-centered experiences and environments and to achieve primal results.

Abbreviations

ICT: Information and Communication Technology; XR: Extended Reality; 2D: Two-dimensional; API: Application Programming Interfaces; CSV: Comma-Separated Values; JSON: JavaScript Object Notation; NLP: Natural Language Processing; NLTK: Natural Language Toolkit; VADER: Valence aware dictionary for sentiment reasoning; NRC: National Research Council Canada; EmoLex: Word-Emotion Association Lexicon; IDE: Integrated development environment; 3D: Three-dimensional.

Acknowledgements

The authors would like to express their gratitude to the SEPA360 project consortium for their valuable feedback during the design of the study. 


\section{Author's contribution}

All authors contributed to the design of the study, literature review, methodology and data analysis. Data collection was conducted by the first author who has also led the data analysis process and the manuscript preparation. Discussions and comments in terms of improving the manuscript were made by all authors on consecutive iterations. The submitted manuscript has been approved by all authors.

\section{Funding}

The present study was supported by European Union through an Erasmus + Strategic Partnership, Key Action 2 grant.

\section{Availability of data and materials}

The data sets used and/or analysed during the current study are available from the corresponding author on reasonable request.

\section{Declarations}

\section{Competing interests}

The authors declare that they have no competing interests.

\section{Author details}

${ }^{1}$ Department of Information and Electronic Engineering, International Hellenic University, Thessaloniki, Greece. ${ }^{2}$ School of Humanities, Hellenic Open University, Patras, Greece. ${ }^{3}$ Department of Physical Education and Sport Sciences, Aristotle University of Thessaloniki, Thessaloniki, Greece. ${ }^{4}$ Faculty of Arts, Cultures and Education, University of Hull, Hull, United Kingdom.

Received: 1 July 2021 Accepted: 13 September 2021

Published online: 26 September 2021

\section{References}

Ahuja, S., \& Dubey, G. (2017). Clustering and sentiment analysis on twitter data (pp. 1-5). https://doi.org/10.1109/TEL-NET. 2017.8343568

Alexander, B., Ashford-Rowe, K., Barajas-Murph, N., Dobbin, G., Knott, J., McCormack, M., Pomerantz, J., Seilhamer, R., Weber, N. (2019). Horizon report 2019 higher education edition. Technical report, EDUCAUSE. Accessed 22 Feb 2021.

Appleton, J. J., Christenson, S. L., Kim, D., \& Reschly, A. L. (2006). Measuring cognitive and psychological engagement: Validation of the student engagement instrument. Journal of School Psychology, 44(5), 427-445. https://doi.org/10. 1002/pits.20303.

Barreda-Ángeles, M., Aleix-Guillaume, S., Pereda-Baños, A. (2020). Virtual reality storytelling as a double-edged sword: Immersive presentation of nonfiction 360-video is associated with impaired cognitive information processing. In Communication monographs (pp. 1-20). https://doi.org/10.1080/03637751.2020.1803496.

Berns, A., Mota, J. M., Ruiz-Rube, I., \& Dodero, J. M. (2018). Exploring the potential of a 360 video application for foreign language learning. In Proceedings of the sixth international conference on technological ecosystems for enhancing multiculturality (pp. 776-780). https://doi.org/10.1145/3284179.3284309.

Boyd, D. M., \& Ellison, N. B. (2007). Social network sites: Definition, history, and scholarship. Journal of Computer-Mediated Communication, 13(1), 210-230. https://doi.org/10.1111/j.1083-6101.2007.00393.x

Bruns, A., Highfield, T., \& Lind, R. A. (2012). Blogs, twitter, and breaking news: The produsage of citizen journalism. Produsing Theory in a Digital World: The Intersection of Audiences and Production in Contemporary Theory, 80, 15-32.

Chou, S. W., \& Liu, C. H. (2005). Learning effectiveness in a web-based virtual learning environment: A learner control perspective. Journal of Computer Assisted Learning, 21(1), 65-76. https://doi.org/10.1111/j.1365-2729.2005.00114.x.

Coller, B. D., \& Shernoff, D. J. (2009). Video game-based education in mechanical engineering: A look at student engagement. International Journal of Engineering Education, 25(2), 308.

Corazza, M., Menini, S., Cabrio, E., Tonelli, S., \& Villata, S. (2020). A multilingual evaluation for online hate speech detection. ACM Transactions on Internet Technology (TOIT), 20(2), 1-22. https://doi.org/10.1145/3377323

Dede, C. (2009). Immersive interfaces for engagement and learning. Science, 323(5910), 66-69. https://doi.org/10.1126/ science.1167311.

DiLullo, C., McGee, P., \& Kriebel, R. M. (2011). Demystifying the millennial student: A reassessment in measures of character and engagement in professional education. Anatomical Sciences Education, 4(4), 214-226. https://doi.org/10.1002/ ase.240.

Dooley, K. (2017). Storytelling with virtual reality in 360-degrees: A new screen grammar. Studies in Australasian Cinema, 11(3), 161-171. https://doi.org/10.1080/17503175.2017.1387357.

Dunaway, J., \& Soroka, S. (2021). Smartphone-size screens constrain cognitive access to video news stories. Information, Communication \& Society, 24(1), 69-84. https://doi.org/10.1080/1369118X.2019.1631367

Dwyer, C., Hiltz, S., \& Passerini, K. (2007). Trust and privacy concern within social networking sites: A comparison of Facebook and myspace. In AMCIS 2007 proceedings (p. 339). https://aisel.aisnet.org/amcis2007/339/.

Elbagir, S., \& Yang, J. (2019). Twitter sentiment analysis using natural language toolkit and vader sentiment. In Proceedings of the international multiconference of engineers and computer scientists (Vol. 122, p. 16).

Fernandez, M. (2017). Augmented virtual reality: How to improve education systems. Higher Learning Research Communications, 7(1), 1-15. https://doi.org/10.18870/hlrc.v7i1.373.

Fredricks, J. A., Blumenfeld, P. C., \& Paris, A. H. (2004). School engagement: Potential of the concept, state of the evidence. Review of Educational Research, 74(1), 59-109. https://doi.org/10.1089/cyber.2017.0295. 
Gaebel, M., Kupriyanova, V., Morais, R., \& Colucci, E. (2014). E-learning in European higher education institutions. European University Association.

Gil de Zúñiga, H., Diehl, T., Huber, B., \& Liu, J. (2017). Personality traits and social media use in 20 countries: How personality relates to frequency of social media use, social media news use, and social media use for social interaction. Cyberpsychology, Behavior, and Social Networking, 20(9), 540-552. https://doi.org/10.1089/cyber.2017.0295

Harrington, C. M., Kavanagh, D. O., Ballester, G. W., Ballester, A. W., Dicker, P., Traynor, O., et al. (2018). 360 operative videos: A randomised cross-over study evaluating attentiveness and information retention. Journal of Surgical Education, 75(4), 993-1000. https://doi.org/10.1016/j.jsurg.2017.10.010.

Henard, F., \& Roseveare, D. (2012). Fostering quality teaching in higher education: Policies and practices. An IMHE Guide for Higher Education Institutions (pp. 7-11). http://learningavenue.fr/assets/pdf/QT\%20policies\%20and\% 20practices.pdf.

Hew, K. F. (2016). Promoting engagement in online courses: What strategies can we learn from three highly rated MOOCS. British Journal of Educational Technology, 47(2), 320-341. https://doi.org/10.1111/bjet.12235.

Hodgson, P., Lee, V. W., Chan, J. C., Fong, A., Tang, C. S., Chan, L., \& Wong, C. (2019). Immersive virtual reality (IVR) in higher education: Development and implementation. In Augmented reality and virtual reality (pp. 161-173). Springer. https://doi.org/10.1007/978-3-030-06246-0_12.

Howe, J. (2006). The rise of crowdsourcing. Wired Magazine, 14(6), 1-4.

Huang, H. M., Rauch, U., \& Liaw, S. S. (2010). Investigating learners' attitudes toward virtual reality learning environments: Based on a constructivist approach. Computers \& Education, 55(3), 1171-1182. https://doi.org/10.1016/j. compedu.2010.05.014.

Hunter, J. (2007). Matplotlib: A 2D graphics environment. Computing in Science Engineering, 9(3), 90-95. https://doi. org/10.1109/MCSE.2007.55.

Hutchins, E. (1995). Cognition in the wild. MIT Press. https://doi.org/10.7551/mitpress/1881.001.0001.

Hutto, C., \& Gilbert, E. (2014). Vader: A parsimonious rule-based model for sentiment analysis of social media text. In Proceedings of the international AAAl conference on web and social media (vol. 8).

Java, A., Song, X., Finin, T., \& Tseng, B. (2007). Why we twitter: Understanding microblogging usage and communities. In Proceedings of the 9th WebKDD and 1st SNA-KDD 2007 workshop on Web mining and social network analysis (pp. 56-65). https://doi.org/10.1145/1348549.1348556.

Kaplan, A., \& Haenlein, M. (2009). Consumer use and business potential of virtual worlds: The case of second life. The International Journal on Media Management, 11(3-4), 93-101. https://doi.org/10.1080/14241270903047008.

Kilteni, K., Groten, R., \& Slater, M. (2012). The sense of embodiment in virtual reality. Presence: Teleoperators and Virtual Environments, 21(4), 373-387. https://doi.org/10.1162/PRES_a_00124

Lampropoulos, G., Keramopoulos, E., \& Diamantaras, K. (2020). Enhancing the functionality of augmented reality using deep learning, semantic web and knowledge graphs: A review. Visual Informatics, 4(1), 32-42. https://doi. org/10.1016/j.visinf.2020.01.001

Liu, D., Bhagat, K. K., Gao, Y., Chang, T. W., \& Huang, R. (2017). The potentials and trends of virtual reality in education. In Virtual, augmented, and mixed realities in education (pp. 105-130). Springer. https://doi.org/10.1007/ 978-981-10-5490-7_1.

Liu, I. F., Chen, M. C., Sun, Y. S., Wible, D., \& Kuo, C. H. (2010). Extending the tam model to explore the factors that affect intention to use an online learning community. Computers \& Education, 54(2), 600-610. https://doi.org/10.1016/j. compedu.2009.09.009.

Loria, S., Keen, P., Honnibal, M., Yankovsky, R., Karesh, D., Dempsey, E., et al. (2014). Textblob: Simplified text processing. In Secondary TextBlob: simplified text processing, 3. https://textblob.readthedocs.io/en/dev/.

Makkonen, P., Lampropoulos, G., \& Siakas, K. (2019). Security and privacy issues and concerns about the use of social networking services. In E-Learn: World conference on e-learning in corporate, government, healthcare, and higher education, association for the advancement of computing in education (AACE) (pp. 457-466). https:// www.learntechlib.org/primary/p/211113/.

Manguri, K. H., Ramadhan, R. N., \& Amin, P. R. M. (2020). Twitter sentiment analysis on worldwide COVID-19 outbreaks. Kurdistan Journal of Applied Research. https://doi.org/10.24017/covid.8.

Mathur, A., Kubde, P., \& Vaidya, S. (2020). Emotional analysis using twitter data during pandemic situation: COVID-19. In 5th International conference on communication and electronics systems (ICCES) (pp. 845-848). IEEE. https://doi. org/10.1109/ICCES48766.2020.9138079.

McKenzie, S., Rough, J., Spence, A., \& Patterson, N. (2019). Virtually there: the potential, process and problems of using 360 video in the classroom. Issues in Informing Science and Information Technology, 16, 211-219. https://doi.org/ $10.28945 / 4318$.

Merchant, Z., Goetz, E. T., Cifuentes, L., Keeney-Kennicutt, W., \& Davis, T. J. (2014). Effectiveness of virtual reality-based instruction on students' learning outcomes in k-12 and higher education: A meta-analysis. Computers \& Education, 70, 29-40. https://doi.org/10.1016/j.compedu.2013.07.033.

Mikropoulos, T. A., \& Natsis, A. (2011). Educational virtual environments: A ten-year review of empirical research (1999-2009). Computers \& Education, 56(3), 769-780. https://doi.org/10.1016/j.compedu.2010.10.020

Mohammad, S. M. (2020). NRC word-emotion association lexicon. http://saifmohammad.com/WebPages/NRC-Emoti on-Lexicon.htm. Accessed 07 Jan 2021.

Mohammad, S., \& Turney, P. (2010). Emotions evoked by common words and phrases: Using mechanical turk to create an emotion lexicon. In Proceedings of the NAACL HLT 2010 workshop on computational approaches to analysis and generation of emotion in text (pp. 26-34). https://www.aclweb.org/anthology/W10-0204/.

Mohammad, S. M., \& Turney, P. D. (2013). Crowdsourcing a word-emotion association lexicon. Computational Intelligence, 29(3), 436-465. https://doi.org/10.1111/j.1467-8640.2012.00460.x.

Olmos, E., Cavalcanti, J. F., Soler, J. L., Contero, M., \& Alcañiz, M. (2018). Mobile virtual reality: A promising technology to change the way we learn and teach. In Mobile and ubiquitous learning (pp. 95-106). Springer. https://doi.org/ 10.1007/978-981-10-6144-8_6. 
Özgüven, N., \& Mucan, B. (2013). The relationship between personality traits and social media use. Social Behavior and Personality: An International Journal, 41(3), 517-528. https://doi.org/10.2224/sbp.2013.41.3.517.

Pallis, G., Zeinalipour-Yazti, D., \& Dikaiakos, M. D. (2011). Online social networks: Status and trends. New Directions in Web Data Management, 1, 213-234. https://doi.org/10.1007/978-3-642-17551-0_8.

Park, C. W., \& Seo, D. R. (2018). Sentiment analysis of twitter corpus related to artificial intelligence assistants. In 5th International conference on industrial engineering and applications (ICIEA) (pp. 495-498). IEEE. https://doi.org/10. 1109/IEA.2018.8387151.

Phuvipadawat, S., \& Murata, T. (2010). Breaking news detection and tracking in twitter. In IEEE/WIC/ACM international conference on web intelligence and intelligent agent technology (Vol. 3, pp. 120-123). IEEE. https://doi.org/10.1109/ WI-IAT.2010.205.

Plutchik, R. (1984). Emotions: A general psychoevolutionary theory. In Approaches to emotion (pp. 197-219).

Plutchik, R., \& Kellerman, H. (1980). Emotion, Theory, Research, and Experience. Academic Press. https://doi.org/10.1016/ B978-0-12-558701-3.50007-7.

Preece, J., Sharp, H., \& Rogers, Y. (2015). Interaction design: Beyond human-computer interaction. Wiley.

Prensky, M. (2001). Digital natives, digital immigrants. On the Horizon, 9(5), 1-6. https://doi.org/10.1108/1074812011 0424816.

Ramteke, J., Shah, S., Godhia, D., \& Shaikh, A. (2016). Election result prediction using twitter sentiment analysis. In International conference on inventive computation technologies (ICICT) (Vol. 1, pp. 1-5). IEEE. https://doi.org/10. 1109/INVENTIVE.2016.7823280.

Ranieri, M., Bruni, I., \& Luzzi, D. (2020). Introducing 360-degree video in higher education: An overview of the literature. Human and Artificial Intelligence for the Society of the Future. https://doi.org/10.38069/edenc onf-2020-ac0032.

Riva, G., Mantovani, F., Capideville, C. S., Preziosa, A., Morganti, F., Villani, D., et al. (2007). Affective interactions using virtual reality: The link between presence and emotions. CyberPsychology \& Behavior, 10(1), 45-56. https://doi. org/10.1089/cpb.2006.9993.

Roche, L., \& Gal-Petitfaux, N. (2017). Using 360 video in physical education teacher education. In Society for information technology \& teacher education international conference, Association for the Advancement of Computing in Education (AACE) (pp. 3420-3425). https://www.learntechlib.org/primary/p/178219/.

Roorda, D. L., Koomen, H. M., Spilt, J. L., \& Oort, F. J. (2011). The influence of affective teacher-student relationships on students' school engagement and achievement: A meta-analytic approach. Review of Educational Research, 81 (4) 493-529. https://doi.org/10.3102/0034654311421793.

Rupp, M. A., Kozachuk, J., Michaelis, J. R., Odette, K. L., Smither, J. A., \& McConnell, D. S. (2016). The effects of immersiveness and future VR expectations on subjective-experiences during an educational 360 video. In Proceedings of the human factors and ergonomics society annual meeting (Vol. 60, pp. 2108-2112). SAGE Publications. https:// doi.org/10.1177/1541931213601477.

Saha, S., Yadav, J., \& Ranjan, P. (2017). Proposed approach for sarcasm detection in twitter. Indian Journal of Science and Technology, 10(25), 1-8. https://doi.org/10.17485/ijst/2017/v10i25/114443

Sherman, W. R., \& Craig, A. B. (2018). Chapter 10: Virtual reality: Past, present, future. In W. R. Sherman \& A. B. Craig (Eds.), Understanding virtual reality. The Morgan Kaufmann series in computer graphics (2nd ed., pp. 780-821). Morgan Kaufmann. https://doi.org/10.1016/B978-0-12-800965-9.00010-6.

Shernoff, D. J., Csikszentmihalyi, M., Schneider, B., \& Shernoff, E. S. (2014). Student engagement in high school classrooms from the perspective of flow theory. In Applications of flow in human development and education (pp. 475-494). Springer. https://doi.org/10.1007/978-94-017-9094-9_24.

Slater, M. (2003). A note on presence terminology. Presence Connect, 3(3), 1-5.

Slater, M. (2018). Immersion and the illusion of presence in virtual reality. British Journal of Psychology, 109(3), 431-433.

Slater, M., Usoh, M., \& Steed, A. (1994). Depth of presence in virtual environments. Presence: Teleoperators \& Virtual Environments, 3(2), 130-144. https://doi.org/10.1162/pres.1994.3.2.130

Snelson, C., \& Hsu, Y. C. (2020). Educational 360-degree videos in virtual reality: A scoping review of the emerging research. TechTrends, 64, 404-412. https://doi.org/10.1007/s11528-019-00474-3

Suchman, L. A. (1987). Plans and situated actions: The problem of human-machine communication. Cambridge University Press.

Surowiecki, J. (2004). The wisdom of crowds: Why the many are smarter than the few and how collective wisdom shapes business, economies, societies, and nations. Doubleday \& Co.

Theureau, J. (2003). Course-of-action analysis and course-of-action centered design. In Handbook of cognitive task design (pp. 55-81). CRC Press. https://doi.org/10.1201/9781410607775.

Ulrich, F., Helms, N. H., Frandsen, U. P., \& Rafn, A. V. (2021). Learning effectiveness of 360 video: Experiences from a controlled experiment in healthcare education. Interactive Learning Environments, 29(1), 98-111. https://doi.org/ 10.1080/10494820.2019.1579234.

van den Broek-Altenburg, E. M., \& Atherly, A. J. (2019). Using social media to identify consumers'sentiments towards attributes of health insurance during enrollment season. Applied Sciences, 9(10), 2035. https://doi.org/10.3390/ app9102035.

Violante, M. G., Vezzetti, E., \& Piazzolla, P. (2019). Interactive virtual technologies in engineering education: Why not $360^{\circ}$ videos? International Journal on Interactive Design and Manufacturing (IJIDeM), 13(2), 729-742. https://doi. org/10.1007/s12008-019-00553-y

Wang, M. T., \& Fredricks, J. A. (2014). The reciprocal links between school engagement, youth problem behaviors, and school dropout during adolescence. Child Development, 85(2), 722-737. https://doi.org/10.1111/cdev.12138.

Wang, M. T., \& Holcombe, R. (2010). Adolescents' perceptions of school environment, engagement, and academic achievement in middle school. American Educational Research Journal, 47(3), 633-662. https://doi.org/10.3102/ 0002831209361209.

Wu, X., Zhu, X., Wu, G. Q., \& Ding, W. (2013). Data mining with big data. IEEE Transactions on Knowledge and Data Engineering, 26(1), 97-107. https://doi.org/10.1109/TKDE.2013.109 
Zhang, D., Zhou, L., Briggs, R. O., \& Nunamaker, J. F., Jr. (2006). Instructional video in e-learning: Assessing the impact of interactive video on learning effectiveness. Information \& Management, 43(1), 15-27. https://doi.org/10.1016/j.im. 2005.01.004.

Zolkepli, I. A., \& Kamarulzaman, Y. (2015). Social media adoption: The role of media needs and innovation characteristics. Computers in Human Behavior, 43, 189-209. https://doi.org/10.1016/j.chb.2014.10.050.

Submit your manuscript to a SpringerOpen ${ }^{\circ}$ journal and benefit from:

- Convenient online submission

- Rigorous peer review

- Open access: articles freely available online

- High visibility within the field

Retaining the copyright to your article

Submit your next manuscript at $\boldsymbol{\Delta}$ springeropen.com 